\title{
Dynamic Structure of the Spot Price of Crude Oil: Does Time Aggregation Matter?
}

\author{
Hajar Aghababa ${ }^{a, *}$, William A. Barnett ${ }^{b}$ \\ ${ }^{a}$ University of Kansas, Lawrence, $K S$ \\ ${ }^{b}$ University of Kansas, Lawrence, KS and Center for Financial Stability, New York, NY
}

June 23, 2015

\begin{abstract}
This paper assess nonlinear structures in the time series data generating mechanism of crude oil prices. We apply well-known univariate tests for nonlinearity, with distinct power functions over alternatives, but with different null hypotheses reflecting the existence of different concepts of linearity and nonlinearity in the time series literature. We utilize daily data on crude oil spot prices for over 26 years, as well as monthly data on crude oil spot prices for 41 years. Investigating the monthly price process of crude oil distinguishes this paper from existing studies of the time series structure of energy markets. All the tests detect strong evidence of general nonlinear serial dependence, as well as nonlinearity in the mean, variance, and skewness functions in the daily spot price process of crude oil. Since evidence of nonlinear dependence is less dramatic in monthly observations, nonlinear serial dependence is moderated by time aggregation in crude oil prices.
\end{abstract}

Keywords: Nonlinearity, energy market, time series analysis, crude oil prices

JEL classification: C22, Q43, C46

* Corresponding author: Tel.: +1 785-550 3083, e-mail addresses: hajar.aghababa@gmail.com

Home address: 331 N Eaton Dr., Lawrence, KS 66049 US

Coauthor's email address: barnett@ku.edu 


\section{Introduction}

The energy sector, in particular the petroleum market, has played a key role in the aggregate economy. The energy sector has historically been influenced by political disturbances. Over the last four decades, the price of petroleum has dramatically increased in response to a series of major events. For instance, during the political unrest in the Middle East, the price of petroleum increased to nearly \$113 per barrel per day in May 2011 after being relatively stable at around $\$ 80$ per barrel per day since the 2008 credit crisis. As a result of such shocks, a large number of studies have focused on the correlation between energy sector disruptions and aggregate economic activity. For example, see Hamilton (1983), Hamilton (2003), and Rotemberg and Woodford (1996). Moreover, short and long-run interactions between the energy sector and other key markets, such as stock markets, have also effected the aggregate economy and have been discussed in the literature. See, e.g., Jawadi, El Hedi Arouri, and Bellalah (2010); El Hedi and Jawadi (2010); and Jawadi and Bellalah (2011).

In view of the importance of the energy sector in the aggregate economy, the dynamic structure of the energy sector is important. In particular, we examine whether time series observations of the market are generated by a linear process or a nonlinear dynamic mechanism. The findings are relevant to choosing appropriate specifications that comply with the data generating mechanism.

To assess the dynamic structure of energy markets, most studies have focused on daily prices of crude oil and other petroleum products. There is little mention of nonlinearity at other time frequencies such as monthly. Main studies using daily observations of the energy market, such as Kyrtsou, Malliaris, and Serletis (2009), have found evidence of nonlinear dependencies in energy market data. Our paper addresses that gap in the literature by incorporating different levels of time aggregation to examine at which time aggregation level the stochastic dependence or nonlinearity cannot be detected in the price of crude oil. We incorporate well-known univariate tests for nonlinearity with distinct power functions over alternatives and tests different null hypotheses. We employ daily spot prices of West Texas Intermediate (WTI) crude oil for over 26 years, as well as monthly time series observations on the real price of WTI crude oil for over 40 years. Incorporating monthly observations distinguishes the approach of this paper from the existing literature.

This paper is organized as follows. Section 2 reviews the role of the energy market in the U.S. economy. Section 3 reviews the related literature. Section 4 describes the data and different unit root analyses. Section 5 discusses the inference methods, as well as providing the results of the nonlinearity tests on daily data and monthly observations. Summary, conclusion, and implication of the study are provided in section 6 . 


\section{The Role of the Energy Market: A Historical Overview}

A large body of literature has found that the U.S. economy is negatively influenced by major disruptions in the supply of crude oil and the consequent escalation in the petroleum price. In early 1970s to early 1980s, the price of oil increased considerably in response to a series of major conflicts in the Middle East. A result was a dramatic decline in the world supply of oil. The first fall in supply in that decade was experienced in late 1973, as a result of the oil embargo by the Organization of the Petroleum Exporting Countries (OPEC). Oil production was cut by five million barrels per day and the price of oil increased 400 percent in six months. See Sill (2007). Crude oil price reaction to a variety of global geopolitical events is shown in Figure 1. The next dramatic increase in oil price occurred as a result of the Iranian Revolution, which began in late 1978 and resulted in a drop of 3.9 million barrels per day of Iran's crude oil production until 1981. In 1980, the Iran-Iraq war began, and by 1981 the OPEC production declined by seven million barrels per day from its level in 1978. The world oil price jumped from \$14 per barrel in 1979 to more than \$35 in 1981.

The Persian Gulf Crisis in 1990 resulted in another sudden increase in crude oil prices. The price of crude oil, which had been relatively stable, escalated from \$16 per barrels per day in July to more than \$36 per barrel per day in September 1990. 
Figure 1: Crude Oil Price Reaction to Variety of Geopolitical and Economic Events

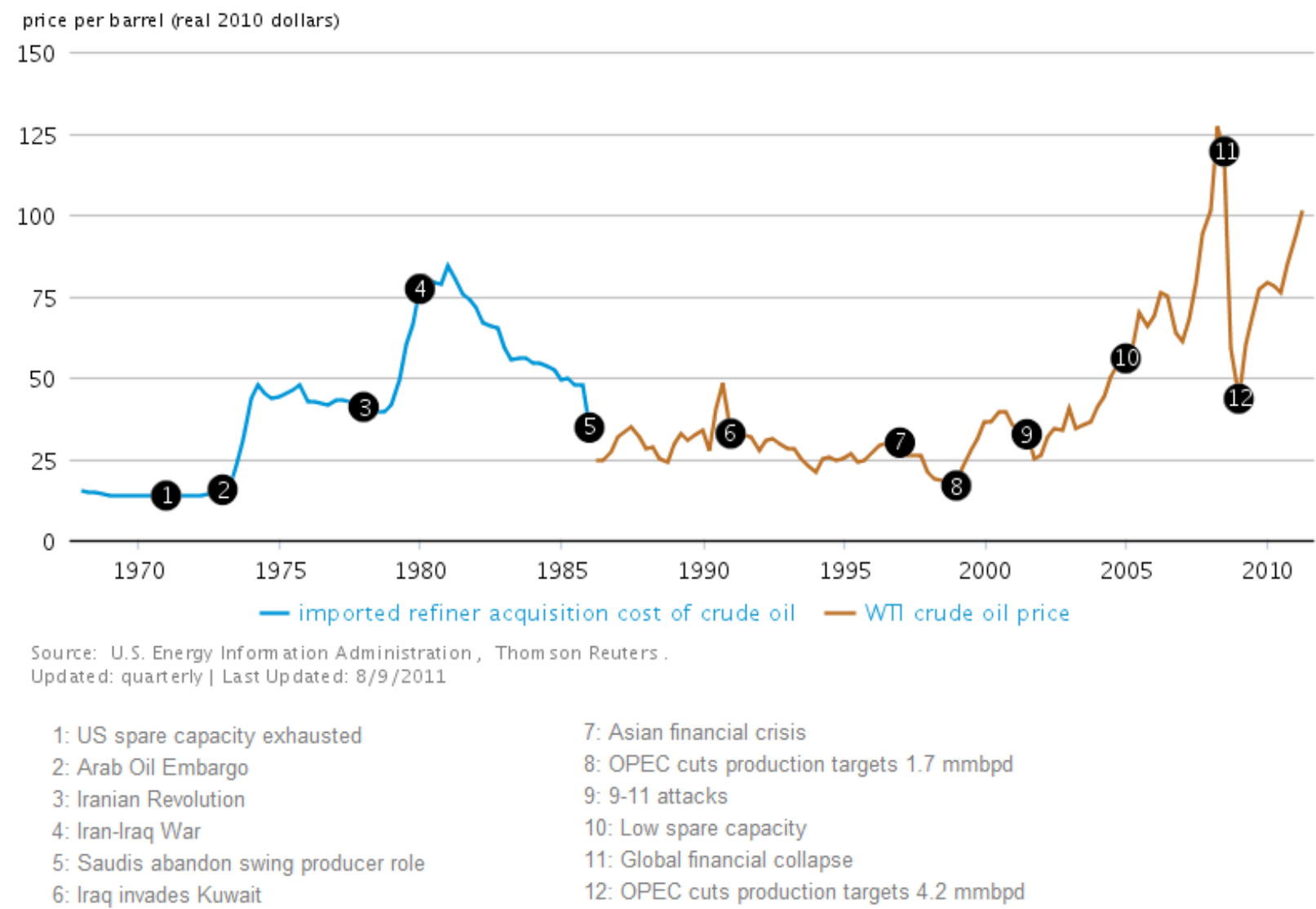

Source: U.S. Energy Information Administration (2012), Thomson Reuters. "Crude Oil Prices React to a Variety of Geopolitical and Economic Events,” What Drives Crude Oil Prices.

After 1990, world oil demand increased dramatically during the global recovery period of 20032007 until the global financial collapse in 2008, when the oil price escalated to $\$ 134$ per barrel per day in July 2008. Oil prices spiked again in 2011, as a result of unrest in the Middle East. The WTI spot price increased to nearly \$120 per barrel per day in April 2011.

Oil price shocks have influenced the U.S. economy through different channels. As Hamilton (1983) noted, seven out of eight postwar U.S. recessions were followed by a significant increase in price of petroleum. In another study, Hamilton (2011) states that the count, as of 2011, stands at ten out of eleven. High oil prices and energy supply disruptions can directly lead to economic downturns in the real business cycle. Moreover, oil price shocks also can influence the aggregate economic activity through monetary policies. If a rise in oil prices increases general price inflation, monetary authorities may adopt restrictive monetary policies, which could slow economic growth ${ }^{1}$.

${ }^{1}$ Robert Pirog (2005), CRS report for congress 
Bernanke, Gertler, and Watson (1997) argue that oil price shocks result monetary policy increases in interest rates, which cause downturns in the economy. Sajjadur \& Serletis (2010) finds that oil price volatility also has an impact on macroeconomic activity. They argue that monetary policy not only reinforces the effects of oil price shocks on output but also contributes to the asymmetric response of output to oil price shocks. The energy sector has always played a crucial role in the economy and has a substantial impact on different sectors. The objective of this paper is investigate the time series structure of energy products' prices.

\section{Nonlinear Dependence and Energy Market in the Literature: An Overview}

A large literature exists on the dynamics structure of daily energy market data. Kyrtsou et al. (2009) discuss a number of widely used univariate tests from dynamical system theory and apply them to the energy market. They apply these tests to daily observations of energy products for nearly 15 years. They find indications consistent with nonlinear dependencies in each market. They also suggest that an effective nonlinear model of energy prices would produce a deeper perception of energy market fluctuations than existing linear models.

Serletis and Gogas (1999) test for deterministic chaos in the North American Natural Gas Liquids Market. They use a Lyapunov exponent estimator and find evidence consistent with a chaotic nonlinear generation process in natural gas liquid markets. Serletis and Andreadis (2004) use daily observations on West Texas Intermediate crude oil prices and Henry Hub natural gas prices and find evidence to support a random fractal structure for North American energy markets. The result is consistent with findings by Serletis and Gogas (1999), who also find evidence of nonlinear chaotic dynamics in North American natural gas liquids markets but not in crude oil and natural gas markets.

Identifying nonlinearities and chaos in financial data have attracted considerable attention as well. Patterson and Ashley (2000) analyze the behavior of stock market return by examining daily, weekly, and monthly returns. Their results indicate that strong nonlinear dependence exists in daily and weekly sample intervals; however the nonlinear dependence is considerably reduced in monthly observations. Kyrtsou and Serletis (2006) discuss univariate tests for independence and hidden nonlinear deterministic structure in economic and financial time series. They apply nonlinear tests to the Canadian exchange rate, using daily data over a 30-year period, and identify a relationship between high-dimensional nonlinearity and shocks. Barnett, Gallant, Hinich, Jungeilges, Kaplan, and Jensen (1995) apply nonlinear tests to detect nonlinear behavior or chaos in various monetary aggregate data series and discuss the controversies that have arisen about the available results. The findings provide a possible explanation for other controversies that exist regarding empirical evidence of chaos in economic data. In another study, Barnett, Gallant, Hinich, Jungeilges, Kaplan, and Jensen (1997) explore the reasons for empirical difficulties with the interpretations of nonlinear and chaos tests' results. They design and run a single-blind controlled competition among five highly regarded tests for nonlinearity or chaos with 10 simulated data series. The results shows that although there are some clear differences 
among the power functions of the tests, associated with subtle differences in the definition of the tests' null hypotheses. But there exists consistency in inferences across the method of inference, if the differences among definitions of the null hypotheses are taken into consideration.

However, studies of energy market fundamentals have mainly focused on daily time series and have not explored the consequences of aggregation over time. This study incorporates monthly observations as well as dividing daily observations into sub-periods. The approach addresses the gap in the literature regarding time series of crude oil prices.

\section{The Data}

Daily Data. The daily data are the spot price on crude oil, WTI, from January 2, 1986 to April 30, 2012, consisting of 6642 observations obtained from the Energy Information Administration (EIA). To perform the analysis on daily data, the data are divided into three sub-periods, such that at least one oil price shock or a counter shock is included in each period of investigation. ${ }^{2}$ The first daily spot price sub-period is from January 2, 1986 to December 30, 1993, consisting of 2039 observations. The second daily spot price sub-period is from January 3, 1994 to December 31, 2003, consisting of 2511 observations. The third daily spot price sub-period is from January 5, 2004 to April 30, 2012, consisting of 2092 observations. The descriptive statistics of daily crude oil spot prices are displayed in Table 1.

Table 1: Summary Statistics of Differenced Log Series - WTI Daily Spot Price

\begin{tabular}{cccccc}
\hline \hline $\begin{array}{c}\text { WTI Daily } \\
\text { Spot Price }\end{array}$ & $\begin{array}{c}\text { Sample } \\
\text { Mean }\end{array}$ & Sample Median & $\begin{array}{c}\text { Standard } \\
\text { Deviation }\end{array}$ & Skewness & Kurtosis \\
\hline $\begin{array}{c}\text { 1/02/1986- } \\
12 / 30 / 1993\end{array}$ & 0.0006 & 0.0004 & 0.0239 & 0.0500 & 5.9722 \\
$01 / 03 / 1994-$ & 0.0001 & 0.0004 & 0.0107 & 0.3715 & 4.8853 \\
$12 / 31 / 2003$ & & & & 4.4603 \\
$01 / 05 / 2004-$ & 0.0002 & 0.0004 & 0.0109 & 0.0010 & \\
$04 / 30 / 2012$ & & & & \\
\hline \hline
\end{tabular}

Monthly Data. The monthly data include real values on the spot price of crude oil, WTI. The sample period of January 1970 to March 2011, consists of 494 observations obtained from the International Financial Statistics (IFS). To carry out the analysis, the monthly data are divided

${ }^{2}$ A countershock is defined to occur, when oil prices experience a sudden decline, resulting from oversupply or recession 
into two sub-samples: January 1970 to December 1991, for a total of 263 observations, and January 1992 to March 2011, for a total of 213 observations. The descriptive statistics of daily crude oil spot prices are displayed are Table 2.

Table 2: Summary Statistics of Differenced Log Series - WTI Monthly Spot Price

\begin{tabular}{cccccc}
\hline \hline $\begin{array}{c}\text { WTI Monthly } \\
\text { Spot Price }\end{array}$ & $\begin{array}{c}\text { Sample } \\
\text { Mean }\end{array}$ & Sample Median & $\begin{array}{c}\text { Standard } \\
\text { Deviation }\end{array}$ & Skewness & Kurtosis \\
\hline $\begin{array}{c}\text { WTI } \\
(1970: 01-2011: 03)\end{array}$ & 0.0030 & 0.000 & 0.0358 & 1.8815 & 24.7710 \\
WTI & 0.00291 & 0.000 & 0.0366 & 3.9287 & 41.8937 \\
$\begin{array}{c}(1970: 01-1991: 12) \\
\text { WTI }\end{array}$ & 0.0031 & 0.0063 & 0.0356 & -0.7759 & 1.9473 \\
$(1992: 01-2011: 03)$ & & & & \\
\hline \hline
\end{tabular}

\subsection{Unit Root Analysis}

Many studies have applied the unit root tests to examine the properties of the energy market's time series in prices and production (Maslyuk \& Smyth, 2008; Maslyuk \& Smyth, 2009). We apply the two most widely used conventional tests, the Augmented Dicky Fuller (ADF) (Dickey \& Fuller, 1981) and the Phillips and Perron (PP) (Phillips \& Perron, 1988) tests, to check for the existence of unit roots in daily and monthly data. In the specification of the unit root regressions for the ADF and the PP tests, using log levels, we included the constant term as well as the time trend to determine whether or not the series are "trend stationary" (TS) model, with a stationary component added to a deterministic trend term. As the results show in Table 3, Table 4, Table 5, and Table 6, we fail to reject the null hypotheses in log levels. As a result, we transform the log levels into first differences of logs throughout the rest of the paper, unless otherwise noted. 
Table 3: Augmented Dickey-Fuller Unit Root Tests - Daily Spot Prices on WTI

Null Hypothesis: The log levels and the differenced log of the series have unit root Lag length: Automatic Selection Based on SIC.

\begin{tabular}{|c|c|c|c|}
\hline Log Level & $\begin{array}{c}\text { Daily Price WTI } \\
\text { 01/02/1986-12/30/1993 }\end{array}$ & $\begin{array}{c}\text { Daily Price WTI } \\
\text { 01/02/1994-12/30/2003 }\end{array}$ & $\begin{array}{c}\text { Daily Price WTI } \\
\text { 01/05/2004-04/30/2015 }\end{array}$ \\
\hline $\begin{array}{l}\text { ADF Test Statisti } \\
\qquad\left(t_{(\widehat{\beta})}\right)\end{array}$ & -3.134 & -2.353 & -1.852 \\
\hline$p$-value* & 0.0984 & 0.4048 & 0.6790 \\
\hline DLog Level & $\begin{array}{c}\text { Daily Price WTI } \\
01 / 02 / 1986-12 / 30 / 1993\end{array}$ & $\begin{array}{c}\text { Daily Price WTI } \\
01 / 02 / 1994-12 / 30 / 2003\end{array}$ & $\begin{array}{c}\text { Daily Price WTI } \\
\text { 01/05/2004-04/30/2015 }\end{array}$ \\
\hline $\begin{array}{l}\text { ADF Test Statisti } \\
\qquad\left(t_{(\widehat{\beta})}\right)\end{array}$ & -18.606 & -29.934 & -23.759 \\
\hline$p$-value* & 0.000 & 0.000 & 0.000 \\
\hline
\end{tabular}

*MacKinnon (1996) one-sided p-values.

Table 4: Philips-Perron Unit Root Test - Daily Spot Prices on WTI Null Hypothesis: The log levels and the differenced log of the series have unit root Bandwidth: (Newey-West automatic) using Bartlett Kernel

\begin{tabular}{|c|c|c|c|}
\hline Log Level & $\begin{array}{c}\text { Daily Price WTI } \\
\text { 01/02/1986-12/30/1993 }\end{array}$ & $\begin{array}{c}\text { Daily Price WTI } \\
\text { 01/02/1994-12/30/2003 }\end{array}$ & $\begin{array}{c}\text { Daily Price WTI } \\
\text { 01/05/2004-04/30/2015 }\end{array}$ \\
\hline PP Test Statistic $\left(Z_{t_{(\hat{\pi})}}\right)$ & -3.379 & -2.723 & -2.457 \\
\hline$p$-value* & 0.0984 & 0.2265 & 0.3497 \\
\hline DLog Level & $\begin{array}{c}\text { Daily Price WTI } \\
01 / 02 / 1986-12 / 30 / 1993\end{array}$ & $\begin{array}{c}\text { Daily Price WTI } \\
01 / 02 / 1994-12 / 30 / 2003\end{array}$ & $\begin{array}{c}\text { Daily Price WTI } \\
\text { 01/05/2004-04/30/2015 }\end{array}$ \\
\hline PP Test Statistic $\left(Z_{t_{(\hat{\pi})}}\right)$ & -37.459 & -49.174 & -43.924 \\
\hline$p$-value* & 0.000 & 0.000 & 0.000 \\
\hline
\end{tabular}

*MacKinnon (1996) one-sided p-values.

The plots of differenced log levels in both frequencies are displayed in Figure 2, Figure 3, Figure 4, Figure 5, Figure 6, and Figure 7 respectively. The kurtosis statistic is particularly large and implies a leptokurtic distribution for the sample periods of January 1970 to March 2011 and January 1970 to December 1991. As shown in Figure 5, the extreme fluctuations are indications of the volatile market and a heavy tail distribution. The first significant deviation occurs around January 1974, when the first oil shock happened in late 1973 and early 1974. Other extreme fluctuations took place as a result of OPEC oversupply about February 1986, the Persian Gulf War around August 1990, and the Global Financial Crisis in 2008. In addition to those events, 
there were other occasions that produced crude oil market price instability. The extreme value of the kurtosis statistic is a reflection of the crude oil market's nature throughout the years. The second sub-period (1992:01 - 2011:03), however, reveals a smaller value than three for kurtosis statistic, which implies a smaller tail-frequency and a flatter top than the normal distribution and Platykurtic distribution (Patterson \& Ashley, 2000).

Table 5: Augmented Dickey-Fuller Unit Root Tests - Monthly Spot Price Indices on WTI Null Hypothesis: The log levels and the differenced log of the series have unit root

Lag length: Automatic Selection Based on SIC.

\begin{tabular}{|c|c|c|c|}
\hline Log Level & $\begin{array}{c}\text { Monthly Price WTI } \\
(1970: 01-2011: 03)\end{array}$ & $\begin{array}{c}\text { Monthly Price WTI } \\
(1970: 01-1991: 12)\end{array}$ & $\begin{array}{c}\text { Monthly Price WTI } \\
\text { (1992:01-2011:03) }\end{array}$ \\
\hline \multicolumn{4}{|l|}{ ADF Test Statistic } \\
\hline$\left(t_{(\widehat{\beta})}\right)$ & -2.409 & -1.468 & -2.944 \\
\hline$p$-value* & 0.374 & 0.8381 & 0.150 \\
\hline DLog Level & $\begin{array}{c}\text { Monthly Price WTI } \\
(1970: 01-2011: 03)\end{array}$ & $\begin{array}{c}\text { Monthly Price WTI } \\
(1970: 01-1991: 12)\end{array}$ & $\begin{array}{c}\text { Monthly Price WTI } \\
(1992: 01-2011: 03)\end{array}$ \\
\hline \multicolumn{4}{|l|}{ ADF Test Statistic } \\
\hline$\left(t_{(\widehat{\beta})}\right)$ & -17.336 & -12.816 & -11.640 \\
\hline$p$-value* & 0.000 & 0.000 & 0.000 \\
\hline
\end{tabular}

*MacKinnon (1996) one-sided p-values.

The sample period for monthly price of crude oil, West Texas Intermediate (WTI), is from 1970:01 to 2011:04 for a total 495

observations. The sample sub-periods for the monthly spot prices: January 1970 - December 1991 and January 1992 - April 2011, a total of 264 and 231 observations, respectively. 
Table 6: Philips-Perron Unit Root Test - Monthly Spot Price Indices on WTI

The log levels and the differenced log of the series have unit root

Bandwidth: (Newey-West automatic) using Bartlett Kernel

\begin{tabular}{|c|c|c|c|}
\hline Log Level & $\begin{array}{c}\text { Monthly Price WTI } \\
(1970: 01-2011: 03)\end{array}$ & $\begin{array}{c}\text { Monthly Price WTI } \\
(1970: 01-1991: 12)\end{array}$ & $\begin{array}{c}\text { Monthly Price WTI } \\
(1992: 01-2011: 03)\end{array}$ \\
\hline PP Test Statistic $\left(Z_{t_{(\hat{\pi})}}\right)$ & -2.290 & -1.288 & -2.88 \\
\hline$p$-value* & 0.4378 & 0.888 & 0.169 \\
\hline DLog Level & $\begin{array}{c}\text { Monthly Price WTI } \\
\text { (1970:01-2011:03) }\end{array}$ & $\begin{array}{c}\text { Monthly Price WTI } \\
(1970: 01-1991: 12)\end{array}$ & $\begin{array}{c}\text { Monthly Price WTI } \\
\text { (1992:01-2011:03) }\end{array}$ \\
\hline PP Test Statistic $\left(Z_{t_{(\hat{\pi})}}\right)$ & -17.336 & -12.666 & -11.640 \\
\hline$p$-value* & 0.000 & 0.000 & 0.000 \\
\hline
\end{tabular}

*MacKinnon (1996) one-sided p-values.

The sample period for monthly price of crude oil, West Texas Intermediate (WTI), is from 1970:01 to 2011:04 for a total 495 observations. The sample sub-periods for the monthly spot prices: January 1970 - December 1991 and January 1992 - April 2011, a total of 264 and 231 observations, respectively. 
Figure 2: Differenced log of West Texas Intermediate (WTI) Spot Price (Dollars/Barrel) - 01/02/1986 - 12/30/1993

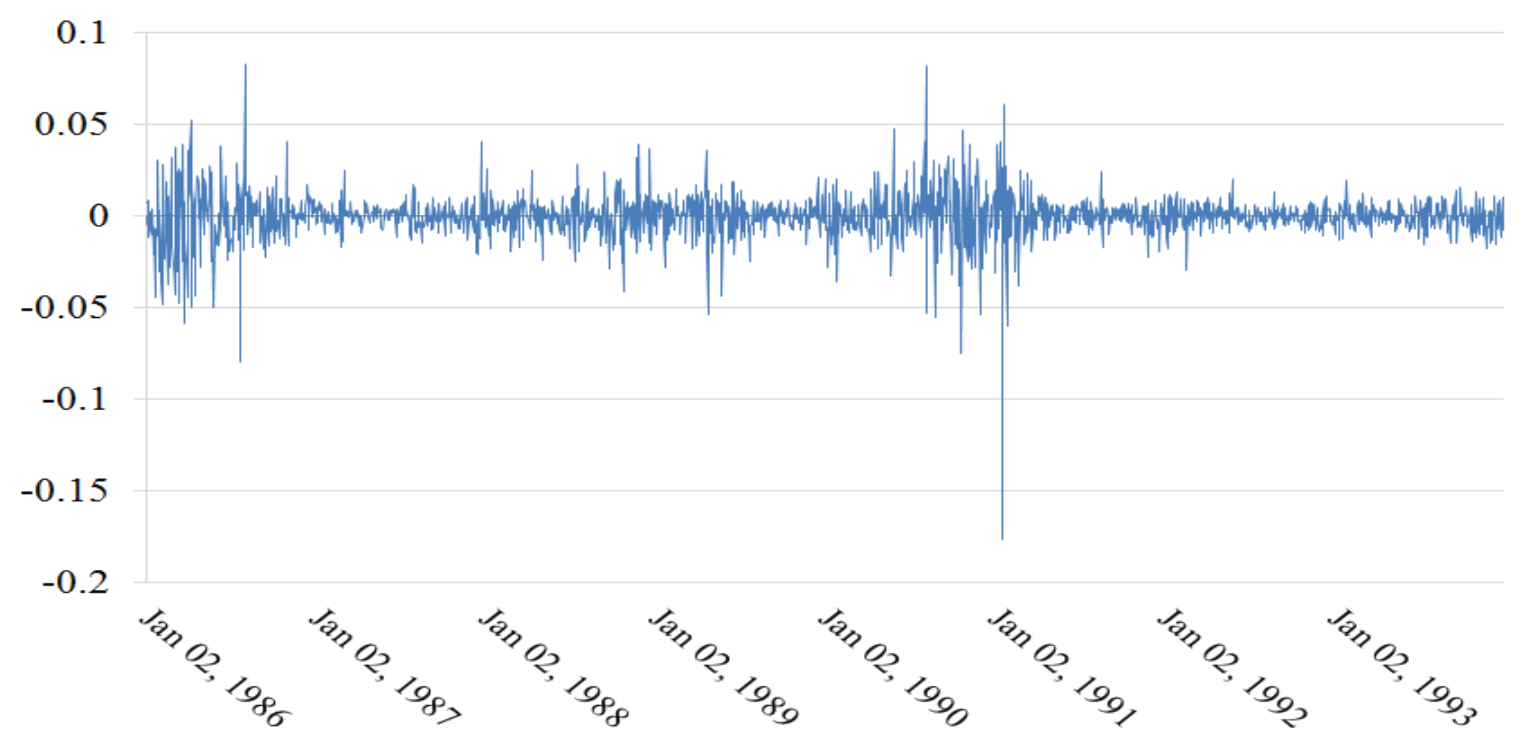

Data Source: Energy Information Administration (EIA)

Figure 3: Differenced log of West Texas Intermediate (WTI) Spot Price (Dollars/Barrel) - 01/05/2004 - 04/30/2012

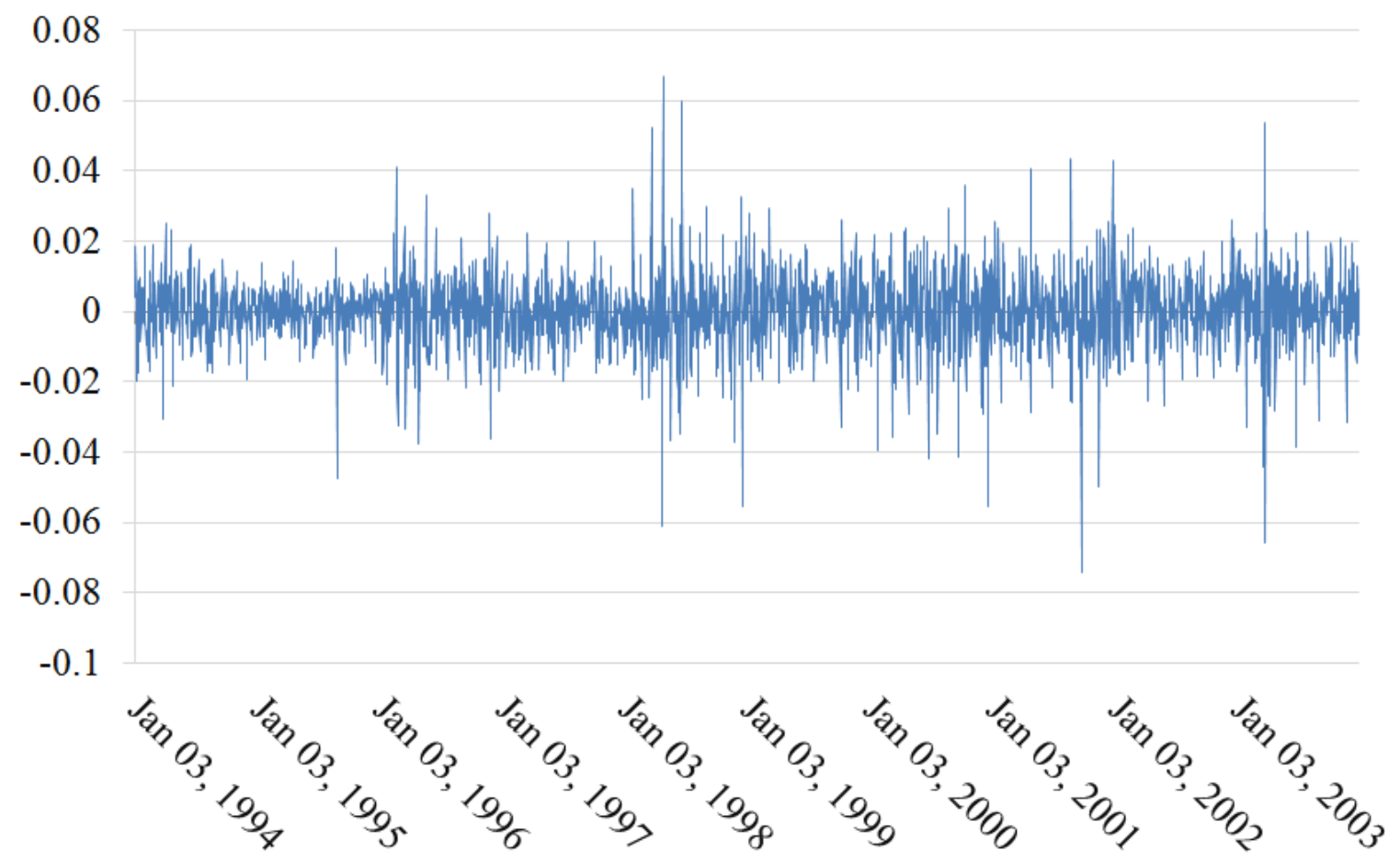


Data Source: Energy Information Administration (EIA)

Figure 4: Differenced log of West Texas Intermediate (WTI) Spot Price (Dollars/Barrel) - 01/05/2004 - 04/30/2012

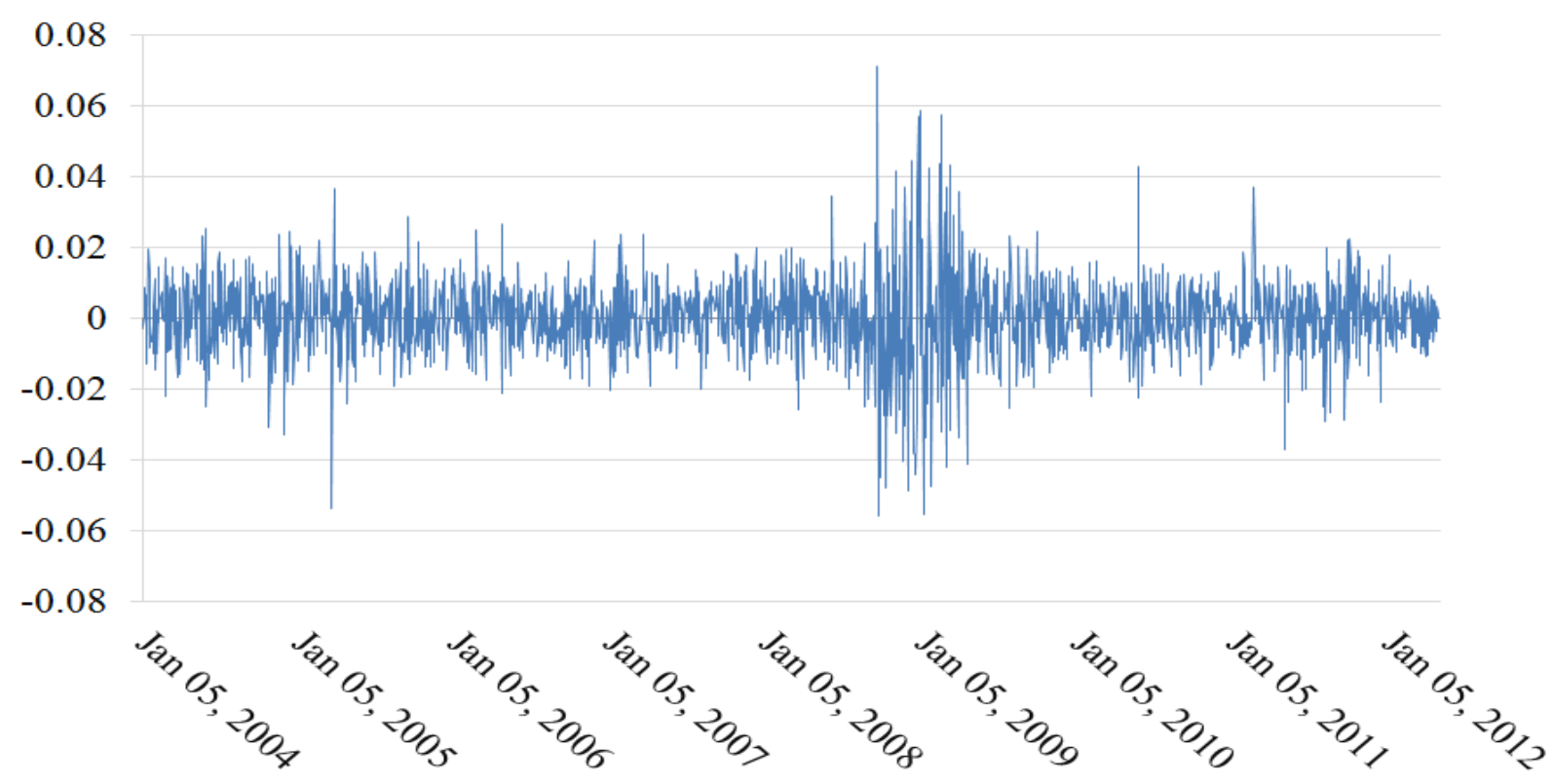

Data Source: Energy Information Administration (EIA) 
Figure 5: Differenced log of West Texas Intermediate (WTI) Monthly Spot Price (Dollars/Barrel)

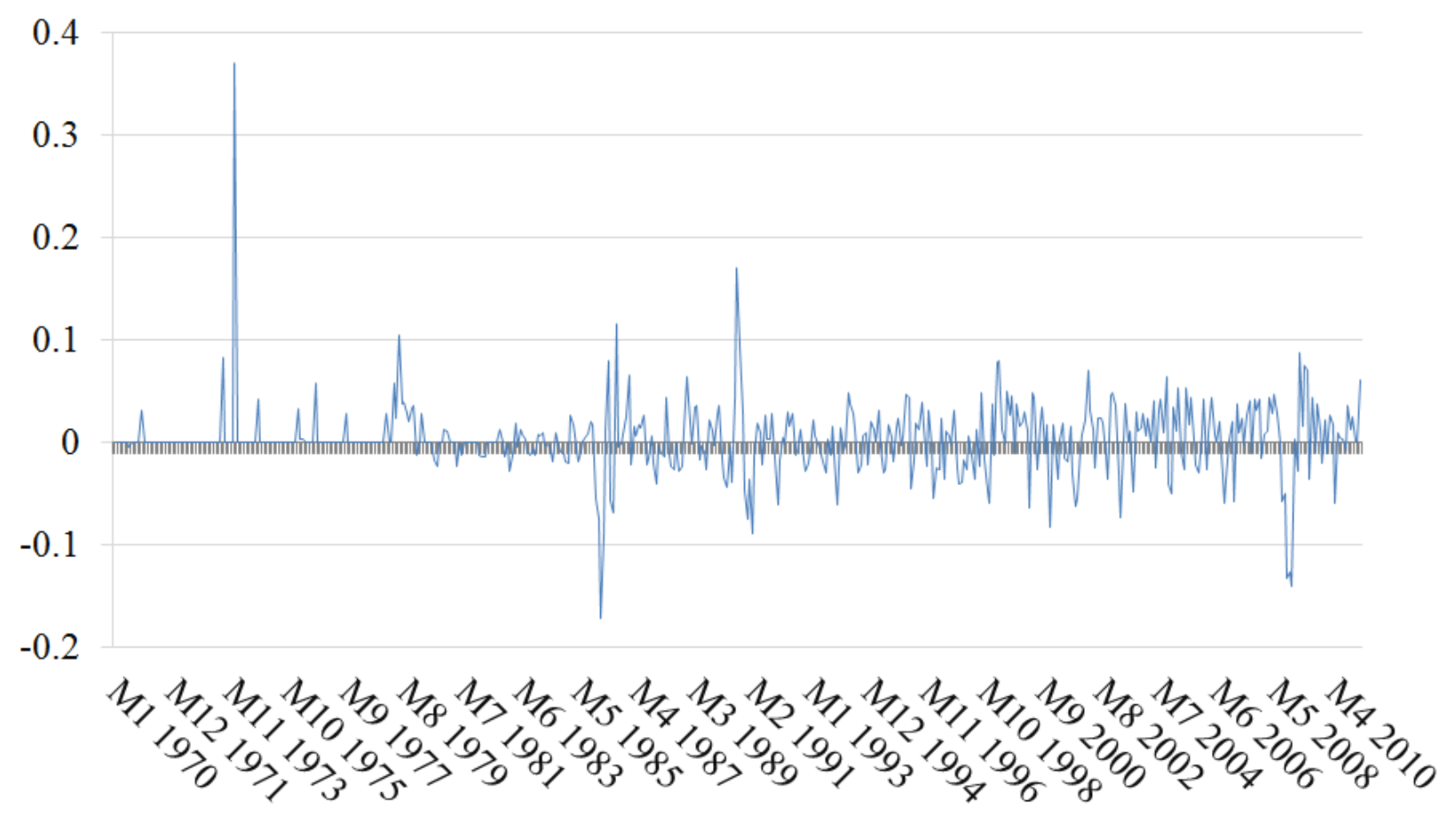

Data Source: Energy Information Administration (EIA) 
Figure 6: Differenced log of West Texas Intermediate (WTI) Monthly Spot Price (Dollars/Barrel) January 1970 - March 2011

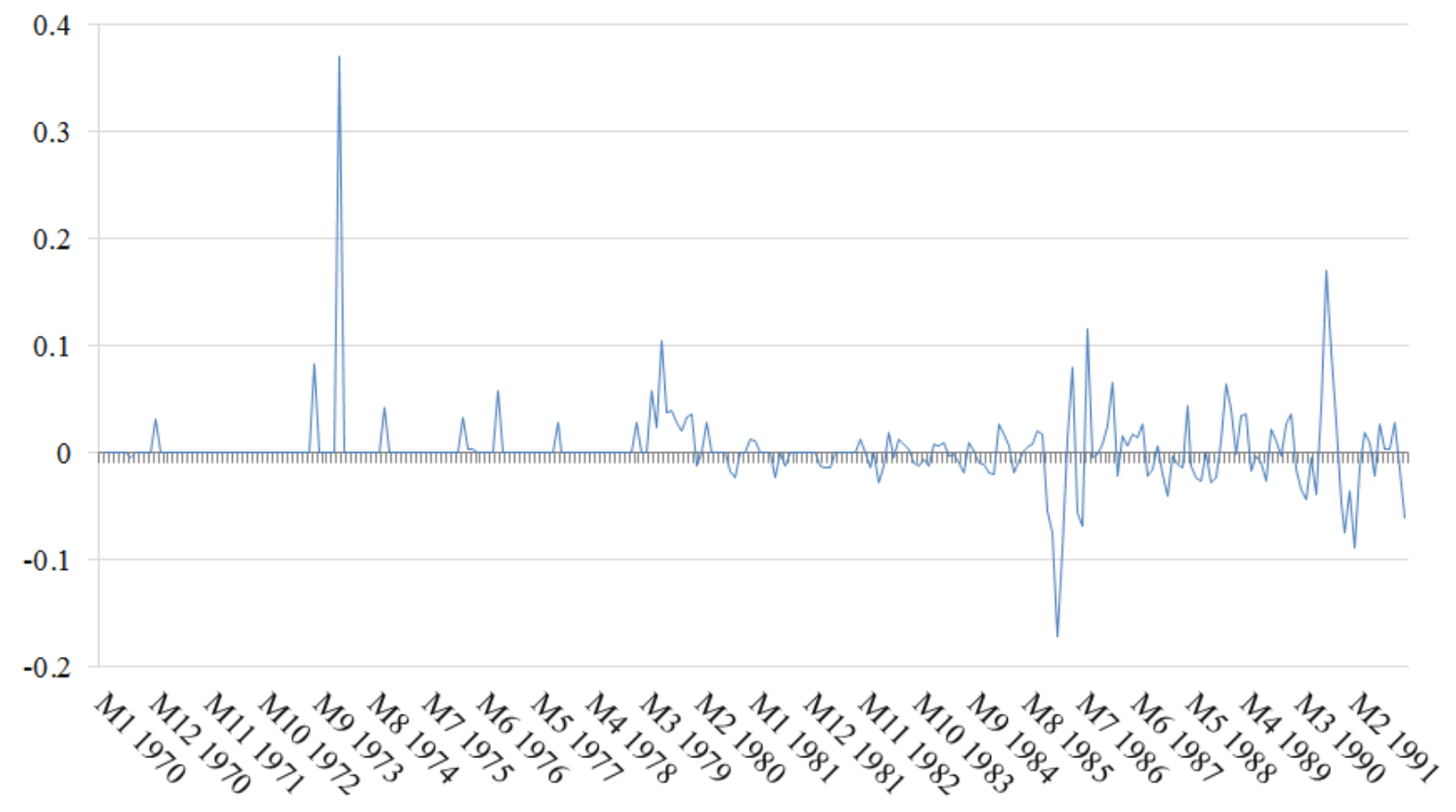

Data Source: Energy Information Administration (EIA)

Figure 7: Differenced log of West Texas Intermediate (WTI) Monthly Spot Price Index (Dollars/Barrel)

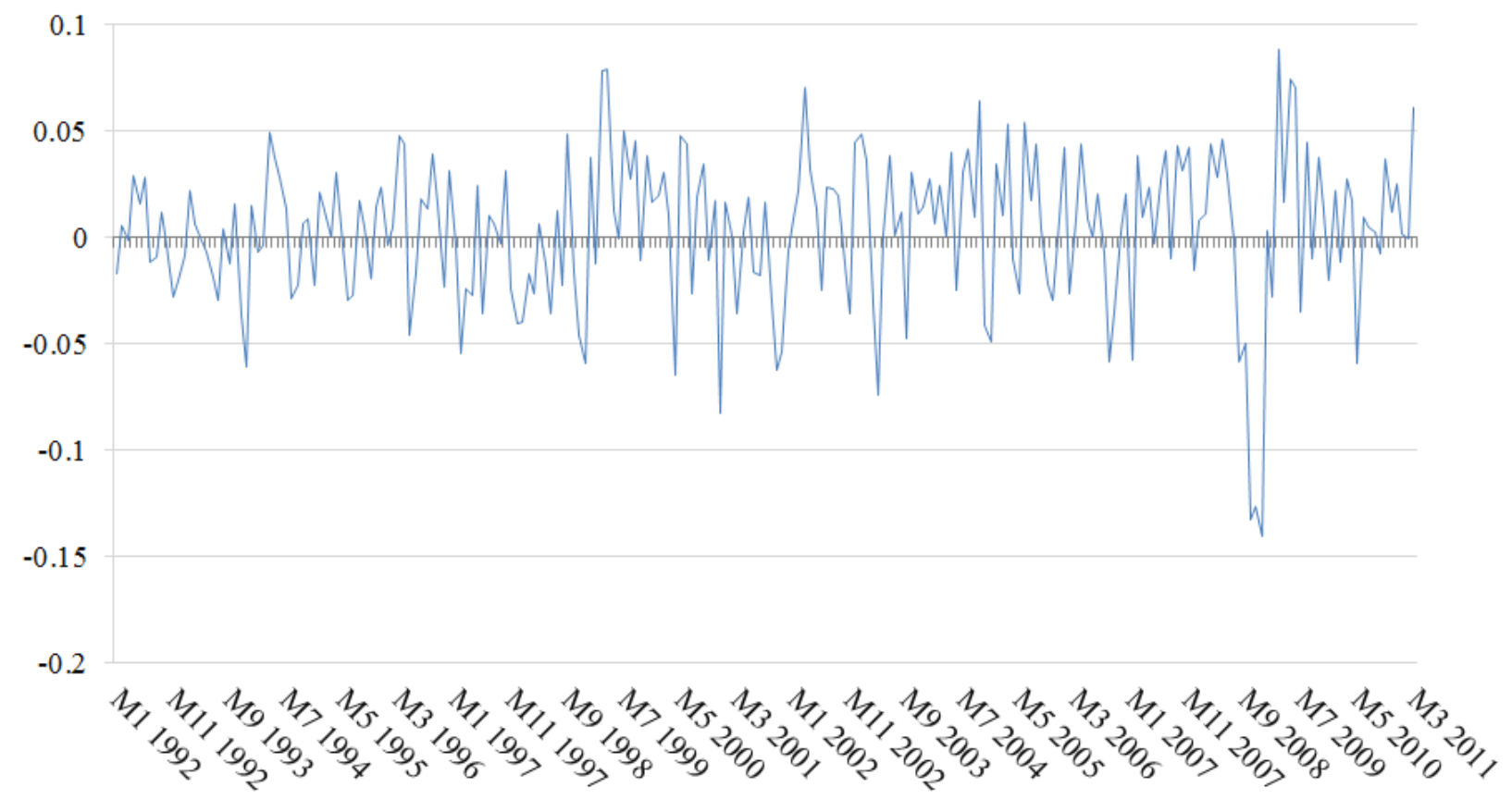

Data Source: Energy Information Administration (EIA 


\section{The Inference Methods}

This section introduces inference methods for statistically detecting nonlinearities in time series data generating mechanisms: The BDS test, Hinich bicovariance test, Hinich bispectrum test, Engle LM test, McLeod-Li test, and Tsay test. All those tests, except the Hinich bispectrum test, require removal of linear serial dependence from the data via prewhitening. Any remaining serial dependence is imputed to a nonlinear data generating mechanism. The Hinich bispectrum test directly tests the data generating mechanism and is invariant to filtering of the data (Patterson \& Ashley, 2000).

\subsection{The BDS Test: A Test for Serial Independence}

The well-known Brock, Dechert, Scheinkman, and LeBaron (1996) test, also known as the BDS test, is one form of portmanteau test for independence, a residual-based test in which the null hypothesis is well stated without a specific alternative hypothesis. The BDS test is a popular test to detect serial independence in time series data. The test can be applied to the estimated residuals of any time series model, if the model can be transformed into a form with independent and identically distributed errors.

The BDS test is used to test the null of linearity and has high power against numerous nonlinear alternatives. The test is applied estimated residual after removing linear structure.

Under the null hypothesis of independent and identically distributed (i.i.d.) disturbances, the BDS test statistic is

$$
\sqrt{n} \frac{C_{m, n}(\epsilon)-C_{1}(\epsilon)^{m}}{\sigma_{m}(\epsilon)},
$$

where $C_{m, n}(\epsilon)$ is the correlation integral, $\sigma_{m}(\epsilon)$ is the asymptotic standard deviation of the numerator, and $m$ is the embedding dimension. The BDS test statistic is a transformation of the correlation function, which asymptotically becomes a standard normal $Z$ statistic under the null hypothesis of whiteness (Barnett et al. 1995). 
The data are prefiltered by fitting a linear ARMA model, and the BDS test is applied against remaining nonlinear structure in residuals. The results with BDS are reported in Tables 7 and 8 for dimensions 2-8 with the value of $\epsilon$ set equal to 1 or 2 standard deviations of the data. ${ }^{3}$

\subsubsection{Results with the BDS Test: Daily Data}

The BDS test statistic for the embedding dimension from two to eight is produced. The inferences are always the same and robust at each embedding dimension. The BDS test results for the three sub-periods of daily spot prices of crude oil are displayed in Table 7. The results indicate the significance at $1 \%$ level based on the asymptotic distribution. The BDS test rejects the null hypothesis of independent and identically distributed observations. Therefore, when the time between observations is not large, the BDS test detects nonlinearity in all cases and shows an underlying nonlinear system.

\subsubsection{Results with the BDS Test: Monthly Data}

The results with monthly data for the complete sample and the two sub-samples are displayed in Table 8. The results reveal interesting facts about the monthly data. Nonlinear dependence is detected in the complete sample, as well as in the first and the second sub-samples. In the second monthly sub-sample, however, nonlinear dependence is not as strong as in the other two cases, particularly when $\epsilon$ is calculated as a unitary multiple of the standard deviation of the series.

The BDS test has high power against numerous nonlinear alternatives. But if linearity is rejected with the BDS test, the results provide little information to distinguish among the existing forms of nonlinearity. Therefore, more focused tests to distinguish among possible forms of nonlinearity should be applied. See Barnett et al. (1997) for more details.

\footnotetext{
${ }^{3}$ Usually, $\epsilon$ is set as a multiple of the standard deviation of the series.
} 
Table 7: BDS Test Z-Statistic (Dimension 2-8) - Daily Spot Price of Crude Oil

\begin{tabular}{|c|c|c|c|c|c|}
\hline \multirow{2}{*}{ Time Period } & \multirow{2}{*}{$\mathrm{m}$} & \multicolumn{4}{|c|}{$\varepsilon$} \\
\hline & & $1 \sigma$ & p-value & $2 \sigma$ & p-value \\
\hline \multirow{7}{*}{$\begin{array}{c}\text { Daily Spot Price } \\
\text { of Crude Oil } \\
\text { (WTI) } \\
(01 / 02 / 1986- \\
12 / 30 / 1993)\end{array}$} & 2 & 15.5429 & 0.000 & 11.5245 & 0.000 \\
\hline & 3 & 19.3594 & 0.000 & 14.1430 & 0.000 \\
\hline & 4 & 22.7812 & 0.000 & 16.2379 & 0.000 \\
\hline & 5 & 26.0529 & 0.000 & 17.7021 & 0.000 \\
\hline & 6 & 29.7307 & 0.000 & 18.9850 & 0.000 \\
\hline & 7 & 33.7293 & 0.000 & 19.8804 & 0.000 \\
\hline & 8 & 38.6443 & 0.000 & 20.6548 & 0.000 \\
\hline \multirow{7}{*}{$\begin{array}{c}\text { Daily Spot Price } \\
\text { of Crude Oil } \\
\text { (WTI) } \\
(01 / 03 / 1994- \\
12 / 31 / 2003)\end{array}$} & 2 & 4.3339 & 0.000 & 6.9100 & 0.000 \\
\hline & 3 & 5.9073 & 0.000 & 9.1127 & 0.000 \\
\hline & 4 & 6.9195 & 0.000 & 9.7959 & 0.000 \\
\hline & 5 & 7.7156 & 0.000 & 10.2777 & 0.000 \\
\hline & 6 & 8.7967 & 0.000 & 10.7110 & 0.000 \\
\hline & 7 & 10.057 & 0.000 & 11.0819 & 0.000 \\
\hline & 8 & 11.3930 & 0.000 & 11.2764 & 0.000 \\
\hline \multirow{7}{*}{$\begin{array}{c}\text { Daily Spot Price } \\
\text { of Crude Oil } \\
\text { (WTI) } \\
(01 / 05 / 2004-- \\
04 / 30 / 2012)\end{array}$} & 2 & 7.8861 & 0.000 & 11.9767 & 0.000 \\
\hline & 3 & 10.2783 & 0.000 & 15.3180 & 0.000 \\
\hline & 4 & 11.8994 & 0.000 & 17.2187 & 0.000 \\
\hline & 5 & 12.8264 & 0.000 & 18.1921 & 0.000 \\
\hline & 6 & 13.8714 & 0.000 & 18.8699 & 0.000 \\
\hline & 7 & 15.0360 & 0.000 & 19.4220 & 0.000 \\
\hline & 8 & 16.2019 & 0.000 & 19.7599 & 0.000 \\
\hline
\end{tabular}

Table 8: BDS Test Z-Statistic (Dimension 2-8) - Monthly Spot Price of Crude Oil

\begin{tabular}{|c|c|c|c|c|c|}
\hline \multirow{2}{*}{ Time Period } & \multirow{2}{*}{$\mathrm{m}$} & \multicolumn{4}{|c|}{$\varepsilon$} \\
\hline & & $1 \sigma$ & p-value & $2 \sigma$ & p-value \\
\hline \multirow{7}{*}{$\begin{array}{c}\text { Daily Spot Price } \\
\text { of Crude Oil } \\
\text { (WTI) } \\
(01 / 02 / 1986- \\
12 / 30 / 1993)\end{array}$} & 2 & 6.6402 & 0.000 & 7.6051 & 0.000 \\
\hline & 3 & 8.2962 & 0.000 & 8.4290 & 0.000 \\
\hline & 4 & 9.5298 & 0.000 & 8.9864 & 0.000 \\
\hline & 5 & 10.5471 & 0.000 & 8.9948 & 0.000 \\
\hline & 6 & 12.6705 & 0.000 & 9.2969 & 0.000 \\
\hline & 7 & 14.6477 & 0.000 & 9.3050 & 0.000 \\
\hline & 8 & 17.0018 & 0.000 & 9.2616 & 0.000 \\
\hline \multirow{7}{*}{$\begin{array}{c}\text { Daily Spot Price } \\
\text { of Crude Oil } \\
\text { (WTI) } \\
(01 / 03 / 1994- \\
12 / 31 / 2003)\end{array}$} & 2 & 6.5397 & 0.000 & 4.2893 & 0.000 \\
\hline & 3 & 8.0014 & 0.000 & 5.3004 & 0.000 \\
\hline & 4 & 8.1749 & 0.000 & 5.8527 & 0.000 \\
\hline & 5 & 8.3150 & 0.000 & 5.9218 & 0.000 \\
\hline & 6 & 8.8078 & 0.000 & 6.2110 & 0.000 \\
\hline & 7 & 9.1136 & 0.000 & 6.2970 & 0.000 \\
\hline & 8 & 9.3985 & 0.000 & 6.2975 & 0.000 \\
\hline \multirow{7}{*}{$\begin{array}{c}\text { Daily Spot Price } \\
\text { of Crude Oil } \\
\text { (WTI) } \\
(01 / 05 / 2004-- \\
04 / 30 / 2012)\end{array}$} & 2 & 2.5360 & 0.0112 & $\begin{array}{c}4.0298 \\
\end{array}$ & 0.001 \\
\hline & 3 & 2.5245 & 0.0116 & 3.9660 & 0.001 \\
\hline & 4 & 2.6035 & 0.0092 & 4.2307 & 0.000 \\
\hline & 5 & 2.2795 & 0.0226 & 4.0933 & 0.000 \\
\hline & 6 & 2.5717 & 0.0101 & 4.1728 & 0.000 \\
\hline & 7 & 2.6174 & 0.0089 & 3.9522 & 0.0001 \\
\hline & 8 & 2.5629 & 0.0104 & 3.7664 & 0.0002 \\
\hline
\end{tabular}




\subsection{Tests for Nonlinearity}

\subsubsection{The Hinich Bicovariance Test}

As noted by Patterson and Ashley (2000), the Hinich bicovariance test assumes that $x_{t}$ is a realization from a third-order stationary stochastic process. The null hypothesis is serial independence. The test statistic is based on the sample bicovariances of the data, where the $(r, s)$ sample bicovariance is defined as

$$
C_{3}(r, s)=(N-s)^{-1} \sum_{t=1}^{N-s} x_{t} x_{t+r} x_{t+s} \quad 0 \leq r \leq s .
$$

The sample bicovariances are a generalization of a skewness measure. The $C_{3}(r, s)$ are all zero for zero mean, serially i.i.d data. Non-zero values for the $C_{3}(r, s)$ from data in which $x_{t}$ depends on lagged cross-products are assumed for $x_{t-i} x_{t-j}$ and higher order terms.

Let $G(r, s)=(N-s){ }^{0.5} C_{3}(r, s)$, and define $X_{3}$ as

$$
X_{3}=\sum_{s=2}^{\phi} \sum_{r=1}^{s-1}[G(r, s)]^{2} .
$$

Under the null hypothesis that $x_{t}$ is a serially i.i.d. process, Hinich \& Patterson (1995) show that $X_{3}$ is asymptotically distributed as $\chi^{2}[\phi(\phi-1) / 2]$ for $\phi<N^{0.5}$. Based on their simulation, they recommend using $\phi=N^{0.4}$. Under the assumption that $E\left(\left(x_{t}\right)^{0.5}\right)$ exists, the $X_{3}$ statistic detects non-zero third-order correlations and can be considered as a generalization of the Box-Pierce portmanteau statistics. See Hinich and Patterson (1985) for more discussion.

\subsubsection{The Hinich Bispectrum Test}

A third-order nonlinear dependence process can be detected by the skewness function in the frequency domain, when the skewness function is not flat as a function of frequency pairs. The definition of the square of the skewness function is shown in Equation 5. This form of the nonlinearity is called third order, since the skewness function is a normalization of the Fourier transform of the third-order autocovariances. That Fourier transform is called the bispectrum. See, e.g., Barnett et al. (1997).

The Hinich bispectrum test is a nonparametric test that examines the third-order moments (bicovariances) of the data in the frequency domain to obtain a direct test for a nonlinear generation mechanism, regardless of any linear independence that might also be present in the 
data. Therefore, when the test reject the null (i.e., the skewness function is flat), there is no need to check whether linear prewhitening has failed to remove all linear serial dependence in the data (Ashley \& Patterson, 2006).

Hinich (1982) developed the asymptotic statistical test for flatness of bispectrum. He argues that the bispectrum in the frequency domain is easier to interpret than multiplicity of the third-order moments $c_{x x x}(r, s): s \leq r, r=0,1,2, \cdots$ in the frequency domain. For an explanation of the computation of Hinich's test statistic, see Barnett and Hinich (1993). For frequencies $f_{1}$ and $f_{2}$ in the principle domain, $\Omega=\left\{\left(f_{1}, f_{2}\right): 0<f_{1}<0.5, f_{2}<f_{1}, 2 f_{1}+f_{2}<1\right\}$, the Hinich bispectrum of the series at frequency pairs $\left(f_{1}, f_{2}\right)$ is the double Fourier transformation of the third-moments function:

$$
B_{x x x}\left(f_{1}, f_{2}\right)=\sum_{r=-\infty}^{r=\infty} \sum_{s=-\infty}^{s=\infty} c_{x x x}(r, s) \exp \left[-2 \pi\left(f_{1} r+f_{2} s\right)\right]
$$

The square of the skewness function $\Gamma^{2}\left(f_{1}, f_{2}\right)$ is defined in terms of the bispectrum as:

$$
\Gamma^{2}\left(f_{1}, f_{2}\right)=\frac{\left|B_{x x x}\left(f_{1}, f_{2}\right)\right|^{2}}{S_{x x}\left(f_{1}\right) S_{x x}\left(f_{2}\right) S_{x x}\left(f_{1}+f_{2}\right)},
$$

where $S_{x x}(f)$ is the ordinary power spectrum of $x_{t}$ at frequency $f$.

If the time series $x_{t}$ is linear, then the squared skewness function $\Gamma^{2}\left(f_{1}, f_{2}\right)$ is constant over all frequency pairs $\left(f_{1}, f_{2}\right)$ in $\Omega$. If $x_{t}$ is Gaussian, the skewness function $\Gamma^{2}\left(f_{1}, f_{2}\right)$ is zero over all frequencies. Hence linearity and Gaussianity can be tested using a sample estimator of the skewness function $\Gamma^{2}\left(f_{1}, f_{2}\right)$. See Hinich (1982) and Barnett and Hinich (1993) for more details on the computation and the test.

\subsubsection{Engle LM Test}

The Engle LM test was proposed by Engle (1982) to examine nonlinearity in the second moment, particularly for ARCH disturbances. The test employs the Lagrangian multiplier procedure after running the OLS regression and saving the residuals. The procedure then regresses the squared residuals on a constant and p lagged values of the squared residuals:

$$
\hat{\varepsilon}_{t}^{2}=\alpha_{0}+\sum_{j=1}^{p} \alpha_{j} \hat{\varepsilon}_{t-j}^{2}+u_{t}
$$


As most Lagrange multiplier tests, the test statistic is based on the $R^{2}$ of the regression. Under the null hypothesis of a linear generating mechanism for $x_{t}, N R^{2}$ for the above regression is asymptotically distributed as $\chi_{p}^{2}$, where $N$ is the sample size.

\subsubsection{The McLeod-Li Test}

McLeod and Li (1983) developed a portmanteau test for nonlinear statistical dependence in the squared-residual autocorrelations of fitted ARMA models. The procedure uses the autocorrelation function of the squares of the prewhitened data and tests whether $\operatorname{corr}\left(x_{t}^{2}, x_{t-j}^{2}\right)$ is nonzero for some $j$. The autocorrelation at lag $j$ for the squared residuals $x_{t}^{2}$ is estimated by

$$
\hat{r}(j)=\frac{\sum_{t=1}^{N}\left(x_{t}^{2}-\hat{\sigma}^{2}\right)\left(x_{t-j}^{2}-\hat{\sigma}^{2}\right)}{\sum_{t=1}^{N}\left(x_{t}^{2}-\hat{\sigma}^{2}\right)} \text {, where } \hat{\sigma}^{2}=\sum_{t=1}^{N} \frac{x_{t}^{2}}{N} \text {. }
$$

Under the null hypothesis that $x_{t}$ is an i.i.d process, McLeod and Li (1983) showed that, for sufficiently large and fixed $L$, the statistic

$$
Q=N(N+2) \sum_{j=1}^{L} \frac{\hat{r}^{2}(j)}{N-j}
$$

is asymptotically $\chi_{L}^{2}$ under the null hypothesis of a linear generating mechanism. They set $L=20$ for their small-sample simulation.

\subsubsection{The Tsay Test}

The Tsay test introduced by Tsay (1986) examines nonlinearity in the mean, as opposed to the Engle (1982) test for nonlinearity in the variance. The Tsay test looks for quadratic serial dependence, using quadratic terms lagged up to $K$ periods.

Let the $K=k(k+1) / 2$ column vectors, $\mathbf{V}_{1}, \ldots, \mathbf{V}_{k}$, contain all the unique cross-products of the form $x_{t-i} x_{t-j}$, where $i \in[i, k]$ and $j \in[j, k]$. Let $\hat{v}_{t, i}$ denote the projection of $v_{t, i}$ onto the subspace 
orthogonal to $x_{t-1}, \ldots, x_{t-k}$, which are the residuals from a regression of $v_{t, i}$ on $x_{t-1}, \ldots, x_{t-k}$. The parameters $\gamma_{i}, \ldots, \gamma_{k}$ are estimated by applying OLS to the regression equation:

$$
x_{t}=\gamma_{0}+\sum_{i=1}^{k} \gamma_{i} \hat{v} i, t+\eta_{t}
$$

Then, the Tsay test statistic is the usual $F$ statistic for testing the null hypothesis that $\gamma_{i}, \ldots, \gamma_{k}$ are all zero.

\subsection{The Results for Nonlinearity Tests}

In our results, we compare daily versus monthly time series structure. All the nonlineartiy test results are shown in two tables, one using the daily spot price of crude oil (Table 9) and the other displaying the monthly inferences (Table 10).

\subsubsection{Daily Data}

The results with the Hinich bicovariance, Hinich bispectrum, McLeod-Li, Engle, and Tsay tests for with daily spot price data are reported in Table 9. ${ }^{4}$ As observed by Patterson and Ashley (2000), those tests are only asymptotically justified. Therefore, the significance levels of all the tests are bootstrapped. See Patterson and Ashley (2000) for further details on the bootstrap simulations. However, in this study all the asymptotic results were similar to the bootstrapped inferences.

\footnotetext{
${ }^{4}$ The nonlinear software was provided by Professor Douglas M. Patterson. The source and instructions on running the toolkit program and on the analysis can be found in Patterson and Ashley (2000), "A Nonlinear Time Series Workshop: A Toolkit for Detecting and Identifying Nonlinear Serial Dependence,” Kluwer Academic Publishers: Norwell. Available at: http://www.wkap.nl/.
} 
Table 9: Significance Level for Nonlinearity Tests - Daily Spot Price of Crude Oil

\begin{tabular}{|c|c|c|c|}
\hline Sample & $\begin{array}{c}\text { Daily Price WTI } \\
\text { 01/02/1986-12/30/1993 }\end{array}$ & $\begin{array}{c}\text { Daily Price WTI } \\
\text { 01/02/1994-12/30/2003 }\end{array}$ & $\begin{array}{c}\text { Daily Price WTI } \\
\text { 01/05/2004-04/30/2015 }\end{array}$ \\
\hline Bicovariance $\phi=N^{0.4}$ & 0.000 & 0.000 & 0.000 \\
\hline $\begin{array}{l}\text { Bispectral (Gaussianity) } \\
\qquad \mathrm{M}=\mathrm{N}^{0.6}\end{array}$ & 0.000 & 0.000 & 0.000 \\
\hline $\begin{array}{l}\text { Bispectral (Linearity) } \\
\qquad M=\mathrm{N}^{0.6}\end{array}$ & 0.000 & 0.001 & 0.000 \\
\hline Engle $(p=5)$ & 0.000 & 0.000 & 0.000 \\
\hline McLeod-Li (L=24) & 0.000 & 0.000 & 0.000 \\
\hline Tsay $(K=5)$ & 0.000 & 0.000 & 0.000 \\
\hline
\end{tabular}

Note: The sample sub-periods for the daily spot prices: January 2, 1986 - December 30, 1993, January 3, 1994 December 31, 2003, and January 52004 - April 30, 2012 consists of 2039, 2511, and 2092 observations, respectively.

In the Hinich bicovariance test, we set $\phi=N^{0.4}$, based on Hinich and Patterson's (1985) simulation, where $N$ is the sample size for each individual series. The test is run with up to 15 lags and with the number of bootstrap iterations at 100. The null hypothesis that $x_{t}$ is a serially i.i.d process is rejected in every case at the $1 \%$ significance level.

The Hinich bispectrum test examines the third order moments (bicovariances) of the data in the frequency domain. This test focuses on nonlinear serial dependence and substantially changes the usage of the sample bicovariance data from the Hinich bicovariance test. The Hinich bispectrum test accepts linearity, if flatness of bispectrum in the frequency domain cannot be rejected, and accepts Gaussianity if the bispectrum is not only flat and also equal to zero (see, e.g., Barnett et. al 1997). The results in Table 9 indicate very small p-values for each market in the case of the asymptotic test. As a result, the null hypothesis of Gaussianity is rejected at the $1 \%$ significance level. Moreover, the individual series all exhibit very small p-values for the 80 percent fractile bispectrum linearity test. Hence, in asymptotic tests, the null hypothesis of the linearity is also rejected at the $1 \%$ significance level for each daily sub-period time series. The rejection of linearity provides strong evidence for the presence of third order nonlinearity in the data generating process (Barnett et. al 1997).

Ashley and Patterson (2006) show that the bispectrum, $B_{x x x}\left(f_{1}, f_{2}\right)$, is consistently estimated using an average of appropriate triple products of the Fourier representation of the observed time series. The average is taken over a square containing $M$ adjacent frequency pairs. Hinich (1982) showed that $M$ must be above $N^{0.5}$ for the estimate of $B_{x x x}\left(f_{1}, f_{2}\right)$ to be consistent. The results here are reported for $M$ set to the integer closest to $N^{0.6}$. 
The Engle LM test examines nonlinearity in the second moment. Under the null hypothesis of a linear generating mechanism for $x_{t}, N R^{2}$ for the regression Equation 6 is asymptotically distributed as $\chi_{p}^{2}$. The results are reported for $\mathrm{p}=5$. The null hypothesis of nonlinearity in the second moment is rejected at $1 \%$ significance level in all cases. Similarly, the null hypothesis of the McLeod and Li test, that $x_{t}$ is an i.i.d process, is also rejected for up to 24 lags at $1 \%$ significance levels. The Tsay test examines nonlinearity in the quadratic terms. Following the existing literature on that test, the value of $\mathrm{k}=5$ is used here. The results, based on the bootstrapped as well as asymptotic distributions, reject the null hypothesis at $1 \%$ significance levels.

The daily data on crude oil prices exhibit clear evidence of nonlinear structure for each considered sub-period. Nonlinearity is evident in the mean, variance, and skewness functions in all of the daily sub-periods. These results are consistent with other findings in the literature, such as Krytsou, Malliaris, and Serletis (2009).

\section{Monthly Data}

The results with monthly crude oil spot prices are displayed in Table 10.

Table 10: Significance Level for Nonlinearity Tests - Monthly Spot Price of Crude Oil

\begin{tabular}{|c|c|c|c|}
\hline Sample & $\begin{array}{c}\text { Monthly Price WTI } \\
(1970: 01-2011: 03)\end{array}$ & $\begin{array}{c}\text { Monthly Price WTI } \\
(1970: 01-1991: 12)\end{array}$ & $\begin{array}{c}\text { Monthly Price WTI } \\
\text { (1992:01-2011:03) }\end{array}$ \\
\hline Bicovariance $\phi=N^{0.4}$ & 0.000 & 0.000 & 0.000 \\
\hline $\begin{array}{l}\text { Bispectral (Gaussianity) } \\
\qquad \mathrm{M}=\mathrm{N}^{0.6}\end{array}$ & 0.000 & 0.000 & 0.000 \\
\hline $\begin{array}{l}\text { Bispectral (Linearity) } \\
\qquad \mathrm{M}=\mathrm{N}^{0.6}\end{array}$ & 0.000 & 0.998 & 0.725 \\
\hline Engle $(\mathrm{p}=5)$ & 0.645 & 0.950 & 0.000 \\
\hline McLeod-Li (L=24) & 1.000 & 1.000 & 0.000 \\
\hline Tsay $(\mathrm{K}=5)$ & 0.002 & 0.003 & 0.001 \\
\hline
\end{tabular}

Note: The sample period for monthly price of crude oil, West Texas Intermediate (WTI), is from 1970:01 to 2011:04 for a total of 495 observations. The sample sub-periods for the monthly spot prices: January 1970 - December 1991 and January 1992 - April 2011, total of 264 and 231 observations, respectively.

The parameter values for each test as with the daily spot prices. The McLeod-Li test and the Engle test have high power against alternatives in the first monthly sample periods and in the sub-sample of January 1970 to December 1991. We cannot reject the null hypotheses of these two tests for those periods of time. However, the null hypotheses of the McLeod-Li test and the Engle test are strongly rejected in the monthly sample of January 1992 to April 2011. 
The results of the Gaussianity asymptotic tests show extremely small p-values for each daily sample. Hence, the null hypothesis of Gaussianity is rejected at the $1 \%$ significance level. The null of linearity cannot be rejected in either sub-samples with the monthly observations. However, the null of linearity for the sample of January 1970 to April 2011 exhibits a very small p-values for the 80 percent fractile bispectrum test. Hence, the null hypothesis of linearity is asymptotically rejected at the $1 \%$ significance level for the first sample of monthly observations. The rejection of linearity provides strong evidence for the presence of the third order nonlinearity in the data generating process (Barnett et al. 1997).

The null hypotheses of the Hinich bicovariance and the Tsay tests are rejected for all the monthly samples.

\section{Conclusions}

The goal of this paper is to examine the nonlinear structure of crude oil price time series data with and without time aggregation. Prior studies in the literature have used daily data with little mention of other energy data frequencies. To address this gap, we incorporate datasets with different frequencies. We apply widely used univariate tests to detect nonlinearity. The tests differ in their definitions of linearity and in the power against alternative hypotheses. Hence they can detect distinct attributes of nonlinear serial dependence in the data. Using the tests jointly can better identify the nature of the nonlinearity that may exist in the data.

When testing for general nonlinearity, the BDS test with both daily data and monthly data revealed similar results and structure. We applied more focused univariate tests to investigate specific forms of nonlinearity. Nonlinear structure was detected in both frequencies, particularly in daily observations. In a few cases with monthly data, we failed to reject the null hypotheses of the tests against specific types of nonlinearity, including nonlinear dependence in the second and third moments of data generating mechanism. Hence, the power of nonlinear dependence tests varies somewhat at different levels of time aggregation of the crude oil daily spot price.

Regardless of time aggregation, general nonlinear serial dependence detected by the BDS test is observable in all data used for this analysis. Strong evidence of nonlinear dependence in second and third moments of the data generating mechanism is discovered in all samples of the daily spot prices. With monthly data, the nonlinearity was detected, but not as intensely as with daily prices. However, in the case of other markets, such as stock market returns, Patterson and Ashley (2000) and others have found that nonlinear structure is much less evident with monthly data.

As observed by Ashley and Patterson (1989), rejection of the null hypothesis of linearity can imply serious misspecifications in the use of linear time series modeling. The evidence for significant nonlinearity in the data generating mechanism in the energy market, especially at high frequencies, calls into question parameter estimates acquired with linear models. Furthermore, 
nonlinear modeling of energy prices would provide more accurate information on energy market fluctuations than linear time series modeling (Kyrtsou et al. 2009).

In addition, nonlinear structure in the energy market observations is an inference relevant to perfect markets (Aghababa, 2012). Under the perfect market assumption of complete contingent claims with perfect competition, perfect arbitrage, and free entry, general equilibrium time solutions are shocked martingales. No information on past realizations that can be used for speculation about future prices. But nonlinear stochastic processes contain structure that can be used for profitable speculation. The energy market is characterized not only by unpredictable exogenous shocks, but by multiple forms of market failure, such as barriers to entry (e.g., cartels on the supply side) and incomplete contingent claims (Aghababa, 2012). As a result, the relevant theory cannot rule out informative nonlinearity, which this study finds. These conclusions are only slightly compromised by time aggregation, unlike other markets in which time aggregation has often been found substantially to compromise nonlinearity findings.

\section{Acknowledgement}

The authors wish to thank Dr. Douglas M. Patterson and Dr. Apostolos Serletis for their valuable suggestions. This study has benefitted from their comments and insights. 


\section{Bibliography}

Aghababa, H. (2012). Nonlinear Analysis and Dynamic Structure in the Energy Market. Ph.D. Dissertation, University of Kansas.

Ashley, R. A., \& Patterson, D. M. (1989). Linear Versus Nonlinear Macroeconomics: A Statistical Test. International Economic Review, 30(3), 685-704.

Ashley, R. A., \& Patterson, D. M. (2006). Evaluating the Effectiveness of State-Switching Time Series Models for U.S. Real Output. Journal of Business and Economic Statistics, 24(3), 266-277.

Barnett, W. A., \& Binner, J. M. (2004). Functional Structure and Approximation in Econometrics (Contributions to Economic Analysis). Amsterdam: Elsevier.

Barnett, W. A., \& Hinich, M. J. (1993). Has Chaos been Discovered with Economic Data. In P. Chen, \& R. H. Day, Evolutionary Dynamics and Nonlinear Economics (Vol. 261, pp. 254-263). Oxford: Oxford University Press.

Barnett, W. A., Gallant, A. R., Hinich, M. J., Jungeilges, J. A., Kaplan, D. T., \& Jensen, M. J. (1995, July). Robustness of Nonlinearity and Chaos Tests to Measurement Error, Inference Method, and Sample Size. Journal of Economic Behavior and Organization, 27(2), 301-320.

Barnett, W. A., Gallant, A. R., Hinich, M. J., Jungeilges, J. A., Kaplan, D. T., \& Jensen, M. J. (1997). A Single-Blind Controlled Competition Among Tests for Nonlinearity and Chaos. Journal of Econometrics, 82(1), 157-192.

Barnett, W. A., Jones, B. E., \& Nesmith, T. D. (2004). Time Series Cointegration Tests and Nonlinearity. In W. A. Barnett, \& J. M. Binner, Functional Structure and Approximation in Econometrics (Contributions to Economic Analysis) (pp. 549-567). Elsevier: Amsterdam.

Bernanke, B. S., Gertler, M., \& Watson, M. (1997). Systematic Monetary Policy and the Effects of Oil Price Shocks. Brookings Papers on Economic Activity, 28(1), 91-157.

Brock, W. A., Dechert, D. W., LeBaron, B., \& Scheinkman, J. (1996). A test for independence based on the correlation dimension. Econometric Reviews, 15(3), 197-235.

Dickey, D. A., \& Fuller, W. A. (1981). Likelihood Ratio Statistics for Autoregressive Time Series with a Unit Root. Econometrica, 49(4), 1057-1072.

El Hedi, A. M., \& Fredj, J. (2010). Short and long-term links between oil prices and stock markets in Europe. Economics Bulletin, 30(1), 817-828. 
Energy Information Administration. (2011). What Drives Crude Oil Prices. Washington, DC.

Engle, R. F. (1982). Autoregressive Conditional Heteroscedasticity with Estimation of the Variance of United Kingdom Inflation. Econometrica, 50(3), 987-1007.

Hamilton, J. D. (1983, April). Oil and the Macroeconomy Since World War II. Journal of Political Economy, 91(2), 228-248.

Hamilton, J. D. (2003, April). What is an oil shock? Journal of Econometrics, 113(2), 363-398.

Hinich, M. J. (1982). Testing for Gaussianity and Linearity of a Statinary Time Series. Journal of Time Series Analysis, 3(3), 169-176.

Hinich, M. J., \& Patterson, D. M. (1985). Evidence of Nonlinearity in Daily Stock Returns. Journal of Business and Economic Statistics, 3(1), 69-77.

Hinich, M. J., \& Patterson, D. M. (1995). Detecting Epochs of Transient Dependence in White. University of Texas at Austin, Unpublished Manuscript.

Jawadi, F., \& Bellalah, M. (2011). Nonlinear mean reversion in oil and stock markets. Review of Accounting and Finance, 10(3), 316-326.

Jawadi, F., El Hedi Arouri, M., \& Bellalah, M. (2010). Nonlinear linkages between oil and stock markets in developed and emerging countries. International Journal of Business, 15(1), 19-31.

Kyrtsou, C., \& Serletis, A. (2006, March). Univariate tests for nonlinear structure. Journal of Macroeconomics, 28(1), 154-168.

Kyrtsou, C., Malliaris, A. G., \& Serletis, A. (2009, May). Energy sector pricing: On the role of neglected nonlinearity. Energy Economics, 31(3), 492-502.

Maslyuk, S., \& Smyth, R. (2008). Unit root properties of crude oil spot and futures prices. Energy Policy, 36(3), 2591--2600.

Maslyuk, S., \& Smyth, R. (2009). Non-linear unit root properties of crude oil production. Energy Economics, 31(1), 109-118.

Maslyuk, S., \& Smyth, R. (2009). Non-linear unit root properties of crude oil production. Energy Economics, 31(1), 109-118.

McLeod, A. I., \& Li, W. K. (1983). Diagnostic checking ARMA time series models using squared residuals autocorrelations. Journal of Time Series Analysis, 4(4), 293-273. 
Patterson, D. M., \& Ashley, R. A. (2000). A Nonlinear Time Series Workshop: A Toolkit for Detecting and Identifying Nonlinear Serial Dependence. New York: Kluwer Academic Publishers.

Patterson, D. M., \& Ashley, R. A. (2000). Analysis of Stock Market Returns. In D. M. Patterson, \& R. A. Ashley, A Nonlinear Time Series Workshop: A Toolkit for Detecting and Identifying Nonlinear Serial Dependence (pp. 95-121). New York: Kluwer Academic Publishers.

Petroleum Chronology of Events 1970 - 2000. (2002). Washington, DC: Energy Information Administration.

Phillips, P. C., \& Perron, P. (1988). Testing for a Unit Root in Time Series Regression. Biometrika, 75(2), 335-346.

Rotemberg, J. J., \& Woodford, M. (1996, November). Imperfect Competition and the Effects of Energy Price Increases on Economic Activity. Journal of Money, Credit and Banking, 28(2 ), 549-577.

Sajjadur, R., \& Serletis, A. (2010). The Asymmetric Effects of Oil Price and Monetary Policy Shocks: A Nonlinear VAR Approach. Energy Economics, 32(6), 1460-1466.

Serletis, A., \& Andreadis, I. (2004, May). Random fractal structures in North American energy markets. Energy Economics, 26(3), 389-399.

Serletis, A., \& Gogas, P. (1999). The North American Natural Gas Liquids Market Are Chaotic. The Energy Journal, 20(1), 83-103.

Sill, K. (2007). The Macroeconomics of Oil Shock. Federal Reserve Bank of Philadelphia Business Review, Q1.

Tsay, R. S. (1986). Nonlinearity Tests for Time Series. Biometrika, 73(2), 461-466. 